\title{
Improved protocol for efficient regeneration of coconut (Cocos nucifera L.) anther derived embryos
}

\author{
D Bandupriya ${ }^{1 *}$ and P Waidyarathne ${ }^{2}$ \\ ${ }^{I}$ Department of Plant Sciences, Faculty of Science, University of Colombo, Colombo 03. \\ ${ }^{2}$ Plant Physiology Division, Coconut Research Institute, Lunuwila.
}

\begin{abstract}
The occurrence of severe shoot necrosis and other constraints such as low frequency of embryo induction and poor regeneration into plants, restrict the use of coconut androgenesis in practice. Fine-tuning of the protocol by addressing the above constraints was carried out with the intention of scaling-up haploid plant production. Out of the carbon types, sucrose and maltose, when added in concentrations of $90.0 \mathrm{gL}^{-1}$ and 120.0 $\mathrm{gL}^{-1}$ showed significantly higher $(\mathrm{p}<0.05)$ embryo $(44.0 \%$ and $36.0 \%$, respectively) production. Out of the concentrations used in the study, 20.0 $\mu \mathrm{M}$ 6-benzylaminopurine (BAP) showed significantly $(\mathrm{p}=0.001)$ higher shoot generation $(47.6 \%)$ as well as significantly $(\mathrm{p}=0.006)$ longer shoot production $(31.7 \%)$ during the study period. The effect of $\mathrm{CaCl}_{2}$ on the reduction of shoot necrosis was also tested. $\mathrm{CaCl}_{2}$ showed a significant $(\mathrm{p}=0.001)$ effect on reducing the shoot necrosis. The lowest occurrence of shoot necrosis $(25.0 \%)$ was observed in $4.0 \mathrm{mM} \mathrm{CaCl}_{2}$ treatment. Continuous sub-culturing of shoots with initial signs of shoot necrosis to elevated $\mathrm{CaCl}_{2}$ levels until the rooting stage facilitated the recovery. Transfer of the shoots frequently into a fresh medium was not beneficial for the suppression of necrosis. Shoots maintained in the medium enriched with $4.0 \mathrm{mM} \mathrm{CaCl}_{2}$ were transferred for acclimatisation, and this is the first report of transferring haploid coconut plants to acclimatisation conditions. The rooted shoots produced through the optimised protocol were acclimatised successfully. The prevention of shoot loss due to shoot necrosis will be beneficial for further refinement of the coconut anther culture protocol.
\end{abstract}

Keywords: Anther culture, calcium chloride, carbon source, regeneration, shoot necrosis.

\section{INTRODUCTION}

Coconut plays a vital role in the economy of tropical countries such as the Philippines, Indonesia, India, and Sri Lanka. Genetic improvement of coconut for high yield and other desirable traits is a priority research area for uplifting the coconut industry. Due to the long life span and high heterozygosity, coconut breeding through conventional methods is a long, difficult and expensive process (Nguyen et al., 2015). Moreover, the production of true hybrids is hampered by high heterozygosity of coconut palm. At present, coconut breeding is done either by mass selection or crossing between varieties that have high variation within a population (Batugal et al., 2009). Thus, the resultant progenies are not true hybrids. Alternative approaches to produce homozygous pure lines in coconut are highly desirable in order to improve coconut plantations. The production of double haploids $(\mathrm{DH})$ is the fastest route to initiate homozygosity in plants and has been experimented withalargenumberofcropspecies(Dunwell, 1985; Abdollahi \& Rashidi, 2018; Bhatia et al., 2018). DHs are produced by doubling the chromosomes of haploid plants, which can occur spontaneously or by chemical treatments, resulting in individuals with two identical copies of each chromosome (Dunwell, 1985).

\footnotetext{
*Corresponding author (dbandupriya@pts.cmb.ac.lk (DD https://orcid.org/:0000-0001-6257-1472)
} 
In higher plants, doublehaploids can be introduced either through androgenesis (anther or microspore culture) or gynogenesis (ovary or megaspore culture). The availability of a few mega spores and the difficulty of fine-dissection of gametes hinder the use of mega spores for haploid plant production (Rajcan et al., 2011).

The development of an effective protocol for DHs and its further application in breeding programmes is the only practical alternative for enhancing the coconut breeding strategy for the production of true hybrids. This could reduce the time required for the development of homozygous populations. Antherculture has been reported by Perera et al. (2008). Some of the critical factors that are required to induce microspore embryogenesis such as culture medium, pollen developmental stage, stress pre-treatment, and anther density have been discussed (Nguyen et al., 2015; Bandupriya et al., 2016). The problems associated with shoot necrosis and shoot death during in vitro culture limit further growth of plantlets up to acclimatisation stage. Moreover, the low frequency of microspore-derived embryo induction and poor plant regeneration restrict the use of anther culture technique in further developments. Thus, the use of boosted $\mathrm{CaCl}_{2}$ concentrations in the regeneration medium and frequent sub-culturing was tested for overcoming shoot necrosis. Further, attempts were made to improve the anther culture protocol by studying the effect of different carbon sources on androgenic induction and of 6-benzylaminopurine (BAP) on plant regeneration efficiency.

\section{METHODOLOGY}

\section{Plant material and explant preparation}

Rachilla was collected from inflorescences of the variety 'Sri Lanka Tall' at three weeks before the splitting (3WBS) stage as described by Perera et al. (2008), from an adult coconut palm growing at Bandirippuwa Estate, Lunuwila, Sri Lanka. At this stage, anthers contain pollen grains at thelate uni-nucleate stage (Perera et al., 2008). The middle portion of each rachillae (containing male flowers) were wrapped in aluminium foil and given a heat shock at $38{ }^{\circ} \mathrm{C}$ for $6 \mathrm{~d}$. Pre-treated anthers were excised from the male flowers and pooled anthers were surface sterilised using $2.0 \%(\mathrm{v} / \mathrm{v})$ commercial bleach $\left(\right.$ Clorox $\left.{ }^{\circledR}\right)$ solution with a few drops of liquid detergent for $10 \mathrm{~min}$, followed by four rinses with sterilised distilled water under aseptic conditions.

\section{Effect of carbon source on androgenesis induction}

Culture initiation and regeneration were based on the methods described by Perera et al. (2009) with modifications. Modified Eeuwens $\mathrm{Y}_{3}$ medium (Eeuwens, 1976) was used in all steps until plants were transferred to the soil. A medium consisted of 100 $\mu \mathrm{M}$ 2, 4-dichlorophenoxyacetic acid (2,4-D) and 100 $\mu \mathrm{M}$ Naphthaleneacetic acid (NAA) was used as the androgenesis induction medium. The effect of the type and concentration of the carbon source on androgenesis induction was studied by culturing the pre-treated anthers into solidified media supplemented with sucrose, maltose and glucose at concentrations of 40, 90, 120 and $150 \mathrm{gL}^{-1}$. After adjusting the $\mathrm{pH}$ to 5.8 , activated charcoal (Heycarb, Sri Lanka) at a concentration of $0.1 \%(\mathrm{w} / \mathrm{v})$ and phytagel $0.25 \%(\mathrm{w} / \mathrm{v})$ were added to the medium and autoclaved at $121^{\circ} \mathrm{C}$ for $20 \mathrm{~min}$. Fifteen anthers were cultured (abaxial side up) per Petri plate $(90 \times 18 \mathrm{~mm})$ each containing $40.0 \mathrm{~mL}$ of culture medium. Five Petri plates were used for each treatment. The Petri plates were incubated in the dark at $27 \pm 1{ }^{\circ} \mathrm{C}$ until embryos emerged. The number of anthers that produced embryos was counted and recorded after 08 months from culture initiation.

\section{Effect of BAP on regeneration}

The embryos were sub-cultured into somatic embryo induction medium with reduced 2,4-D $(70.0 \mu \mathrm{M})$ solidified with $0.25 \%(\mathrm{w} / \mathrm{v})$ phytagel, followed by maturation medium devoid of any growth regulators and solidified with $0.30 \%(\mathrm{w} / \mathrm{v})$ phytagel. Mature embryos were collected, bulked and cultured on the germination medium supplemented with different concentrations of BAP $(5.0,10.0,20.0$, and $25.0 \mu \mathrm{M})$ for further proliferation and shoot initiation. Three sub cultures were added into the same fresh medium until shoots emerged. Well-developed germinating embryos were then transferred to regeneration medium supplemented with $0.45 \mu \mathrm{M}$ gibberellic acid $\left(\mathrm{GA}_{3}\right)$. Cultures were maintained for 6 wks in each media mentioned above before being transferred to the next medium. Finally, continuous sub-culturing was done at 6 -week intervals (unless otherwise stated) into fresh $\mathrm{GA}_{3}$ containing media until shoots developed. All culture media contained 0.1 $\%(\mathrm{w} / \mathrm{v})$ activated charcoal. The cultures were maintained in the dark at $27 \pm 1{ }^{\circ} \mathrm{C}$ until the embryos germinated. The germinated embryos (with shoot sprouts) were then exposed to $16 \mathrm{~h}$ photoperiod (PAR; $25 \mu \mathrm{molm}-2 \mathrm{~s}^{-1}$ ). The number of embryos converted into shoots was counted. Shoots longer than $1.5 \mathrm{~cm}$ was counted in each treatment after 08 months from the first culture of embryos into BAP containing medium. The experiment was repeated three times.

\section{Rooting and acclimatisation of anther cultured plants}

Regenerated shoots were transferred to a medium 
containing $0.5 \mu \mathrm{M}$ indole acetic acid (IAA) to induce rooting. Once the roots developed, the plantlets were transferred to a liquid medium supplemented with the same concentration of IAA. Plants were maintained in a medium supplemented with high $\mathrm{CaCl}_{2}(4.0 \mathrm{mM})$ until they were transferred to the soil medium for acclimatisation. Plants with 3-4 well-developed leaves and a healthy root system (Figure 3c) were carefully removed from the liquid medium and each plant was transferred to a propagator containing a potting mixture of sand, soil, and coir dust (1:1:1).

\section{Reduction in shoot necrosis}

Two methods were tested for the reduction of shoot necrosis at shoot multiplication stage. To determine the effect of $\mathrm{CaCl}_{2}$ on shoot necrosis, different levels of $\mathrm{CaCl}_{2}(2.0,3.0$, and $4.0 \mathrm{mM})$ were incorporated into germination medium and the same levels were maintained until plants were transferred to soil. Twenty germinating embryos were used for each treatment and the number of plants showing necrosis in each treatment was recorded.

Sub-culturing the shoots into a fresh shoot multiplication medium at 3-wk intervals instead of $6 \mathrm{wks}$ was also attempted. A new set of anther-derived shoots was used for this experiment. Eight shoots were used for each treatment and the experiment was carried out twice.

\section{Experimental design and data analysis}

The experiment was designed as a two-factor factorial laid on a completely randomised design (CRD) to determine the effect of carbon source on androgenesis induction. Three sugar types and four concentrations were considered as factors. The experiment was repeated three times. Percentage of embryo production data were analysed using two-way ANOVA after confirming the normality of the data with Anderson Darling normality test $(\mathrm{AD}=0.622, \mathrm{p}=0.093)$. Post-hoc evaluations were done with Tukey's test to find the best sugar type with the correct concentration combination.

The experiment to determine the effect of four BAP concentrations on shoot regeneration was designed as a simple CRD experiment with three replicates. The percentage of embryos converted into shoots and the percentage of embryos that produced shoots longer than $1.5 \mathrm{~cm}$ were tested for normality with Anderson Darling test, and one-way ANOVA was used for data analysis.
Elucidating the effect of $\mathrm{CaCl}_{2}$ on the reduction of shoot necrosis was done using three different $\mathrm{CaCl}_{2}$ concentrations in a simple CRD experiment. Twenty germinating embryos were used in each treatment.

Binary logistic models were used to compare the probability of shoot necrosis (as it is a binary response) based on the $03 \mathrm{CaCl}_{2}$ concentrations as a categorical predictor and to compare the effect of the number of subcultures on necrosis.

\section{RESULTS AND DISCUSSION}

Androgenesis was successfully induced in cultured anthers of coconut (Figure 1a-d). Shoots emerged either through a germination point in the embryo or by splitting the haustorial tissue. Single or multiple shoots were successfully developed into complete plantlets.

\section{Effect of type of sugar and concentration on embryo production}

Androgenesis efficiency was determined based on the percentage number of embryos produced in cultured anthers under different sugar treatments. The results revealed that the concentration and the type of sugar and their interaction indicate the effect of sugar type on the level of embryo production, is dependent on the sugar concentration.

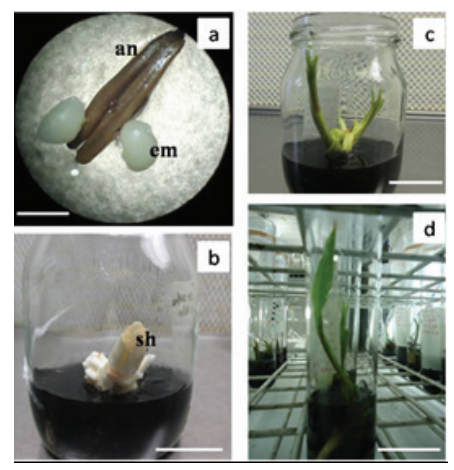

Figure 1: Plant regeneration through coconut anther culture. a embryos (em) derived from anthers (an) after three months of culture initiation (Bar $2 \mathrm{~mm}$ ); b - germinating embryo, the emerging shoot $(\mathrm{Sh})$ through a germination point in the embryo (Bar $2.0 \mathrm{~cm}$ ); c - multiple shoots developed from a single embryo (Bar $2.5 \mathrm{~cm}$ ); d - complete plantlet (Bar 4.0 $\mathrm{cm})$ 
Embryo production was promoted in all four sucrose concentrations. Post hoc evaluation of the interaction effect revealed that the $90 \mathrm{gL}^{-1}$ sucrose concentration performed superior to the other sugar treatments (Figure 2 ) and recorded the highest percentage of embryo production (44.0\%, Figure 2). There was a reduction in embryo production with the increase of sucrose concentration in the medium. The incorporation of maltose instead of sucrose showed a reduction in embryo production when maltose was added either as $40.0 \mathrm{gL}^{-1}$ or
$90.0 \mathrm{gL}^{-1}$ concentration. Maltose added at a concentration of $120.0 \mathrm{gL}^{-1}$ produced significantly higher embryo production equal to $90.0 \mathrm{gL}^{-1}$ sucrose. The effect of higher concentrations (especially $150.0 \mathrm{gL}^{-1}$ ) on embryo production was found to be unfavourable and showed a reduced embryo production in both sucrose and maltose. Interestingly at $120.0 \mathrm{gL}^{-1}$ concentration, both sucrose and maltose showed a similar production of embryos. In general, glucose at all concentrations showed the least production of embryos (Figure 2).

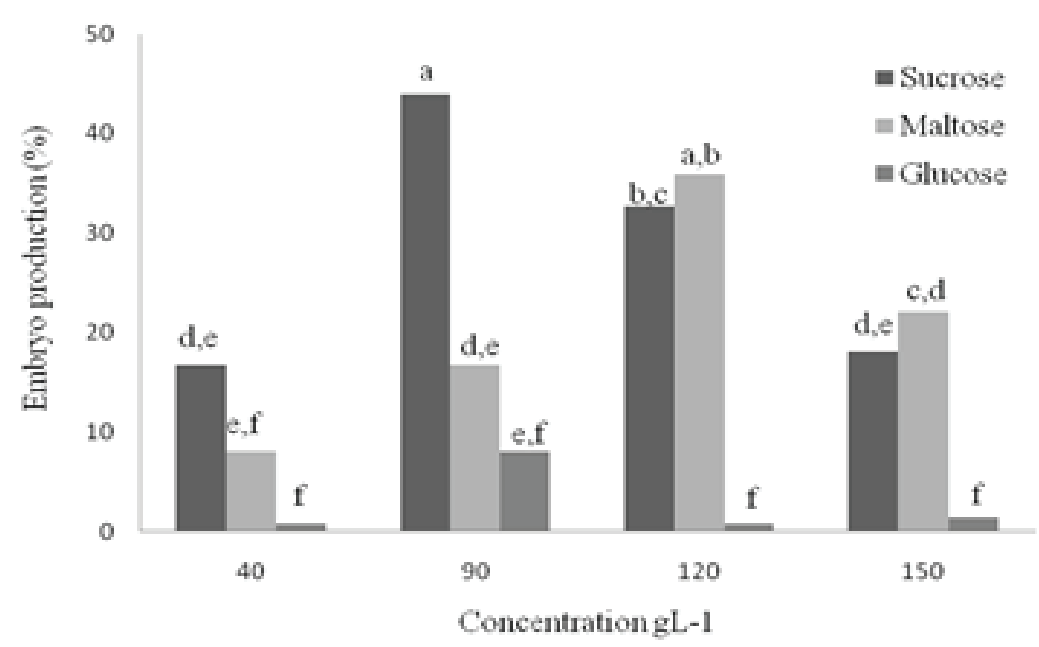

Figure 2: Effect of different sugar types and concentrations on androgenic responses of coconut anthers in androgenesis induction medium. Percentages (mean) with different letters of each parameter are significantly different $(\mathrm{p}<0.05)$.

\section{Effect of BAP on shoot regeneration}

Results revealed that the different concentrations of BAP act significantly on embryos to generate shoots $(\mathrm{F}=16.5$, $\mathrm{p}=0.001$ ) and to produce healthy shoots (longer than $1.5 \mathrm{~cm}$ ) eight months after embryos are transferred to germination medium $(\mathrm{F}=9.22, \mathrm{p}=0.006)$.

Out of the concentrations used in the study, $20.0 \mu \mathrm{M}$
BAP showed significantly high shoot generation as well as significantly longer shoots during the study period (Table 1). The percentage of embryos converted to shoots in the $20.0 \mu \mathrm{M}$ BAP concentration was threefold compared to the control medium supplemented with 5.0 $\mu \mathrm{M}$. Further increase of BAP concentration reduced the conversion of embryos into shoots (Table 1).

Table 1: Effect of different BAP concentrations in the germination medium on plant regeneration in anther culture of coconut

\begin{tabular}{|c|c|c|}
\hline $\begin{array}{c}\text { Concentration of BAP } \\
(\mu \mathrm{M})\end{array}$ & $\begin{array}{l}\text { Percentage embryos converted } \\
\text { to produce shoots* }\end{array}$ & $\begin{array}{l}\text { Percentage embryos with shoots } \\
\text { longer than } 1.5 \mathrm{~cm}^{*}\end{array}$ \\
\hline 5.0 & $15.74^{\mathrm{B}}$ & $07.87^{\mathrm{B}}$ \\
\hline 10.0 & $19.91^{\text {в }}$ & $15.74^{\mathrm{B}}$ \\
\hline 20.0 & $47.62^{\mathrm{A}}$ & $31.75^{\mathrm{A}}$ \\
\hline 25.0 & $27.78^{\mathrm{B}}$ & $19.91 \mathrm{AB}$ \\
\hline
\end{tabular}

\footnotetext{
A,B Means with the same letters along the columns are not significantly different at $\mathrm{p}<0.05$ at $95 \%$ confidence level
} 


\section{Effect of $\mathrm{CaCl}_{2}$ on shoot necrosis}

Shoots derived through androgenesis and raised in regeneration medium [supplemented with normal $\left.\mathrm{CaCl}_{2}(2.0 \mathrm{mM})\right]$ were affected by shoot necrosis and eventually died (Figure 3a). The symptoms started at either in leaves or immature stem in almost all the cultures. This serious problem made it difficult to raise plantlets up to acclimatisation stage. In order to elucidate the effect of $\mathrm{CaCl}_{2}$ on the reduction of shoot necrosis, shoots derived from coconut anthers were cultured in the germination medium supplemented with elevated $\mathrm{CaCl}_{2}$ concentrations. The germination medium used in this particular experiment comprised the best BAP $(20.0 \mu \mathrm{M})$ concentration, which was determined in a previous experiment. It was found that $\mathrm{CaCl}_{2}$ can cause a significant effect on shoot necrosis (G-square $=13.63$, $p$ $=0.001$ ). The results of goodness-of-fit tests (Deviance, Pearson \& Hosmer-Lemeshow) are all greater than the significance level of 0.05 (Chi-Square $=0.64, p=0.72)$, which indicates that the use of binary logistic models is appropriate.

Table 2: The effect of $\mathrm{CaCl}_{2}$ concentration on the reduction of shoot necrosis

\begin{tabular}{lc}
\hline $\mathrm{CaCl}_{2}$ Concentration $(\mathrm{mM})$ & Percentage necrosis Mean $\pm \mathrm{SE}$ \\
\hline 2.0 & $84.21 \pm 8.59^{\mathrm{A}}$ \\
3.0 & $66.7 \pm 12.6^{\mathrm{A}}$ \\
4.0 & $25.00 \pm 11.2^{\mathrm{B}}$ \\
\hline
\end{tabular}

${ }^{\mathrm{A}, \mathrm{B}}$ Means with the same letters along the columns are not significantly different at $\mathrm{p}<0.05$ at $95 \%$ confidence level

According to the results presented in Table 2, plantlets treated with $2.0 \mathrm{mM} \mathrm{CaCl}{ }_{2}$ concentration showed significantly high necrosis than with $4.0 \mathrm{mM}$ treatment. Three millimolar $(3.0 \mathrm{mM}) \mathrm{CaCl}_{2}$ and $4.0 \mathrm{mM} \mathrm{CaCl}_{2}$ concentrations also showed statistical significance for having different levels of necrosis in respective cultures. However, there was no significantly different occurrence of necrosis between the $\mathrm{CaCl}_{2}$ concentrations $2.0 \mathrm{mM}$ and $3.0 \mathrm{mM}$. The highest level of shoot necrosis $(84.21$ \%) was observed in the medium containing $2.0 \mathrm{mM}$ $\mathrm{CaCl}_{2}$, which is the concentration present in the normal $\mathrm{Y}_{3}$ medium used in routine culturing.

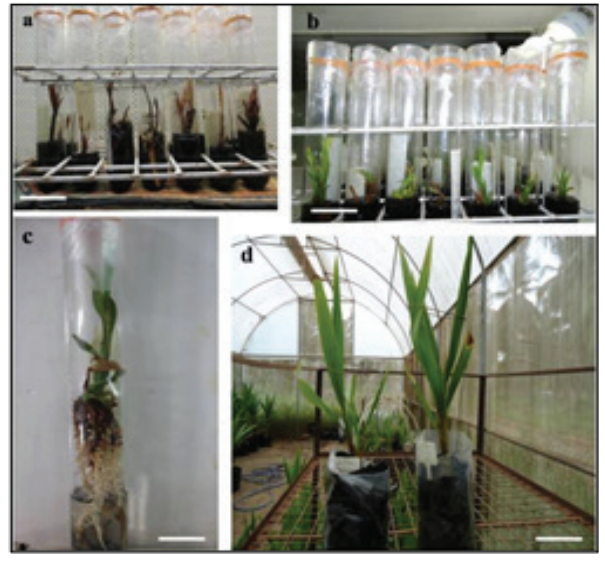

Figure 3. The effect of $\mathrm{CaCl}_{2}$ concentration on the reduction of shoot necrosis. a - dying shoots in the regeneration medium (supplemented with $2.0 \mathrm{mM} \mathrm{CaCl}$ ) due to shoot necrosis (Bar $4.0 \mathrm{~cm}$ ); b - healthy shoots in regeneration medium supplemented with $4.0 \mathrm{mM} \mathrm{CaCl}_{2}(\mathrm{Bar} 3.0 \mathrm{~cm}) ; \mathrm{c}$ - complete plantlet in the rooting medium (Bar $2.0 \mathrm{~cm}$ ); $\mathrm{d}$ - plants at acclimatisation stage (Bar $6.0 \mathrm{~cm})$

Continuous sub-culturing of the shoots with initial signs of shoot necrosis into media supplemented with 4.0 $\mathrm{mM} \mathrm{CaCl}_{2}$ until they developed a good root system has facilitated the recovery. Shoots maintained in the medium enriched with $4.0 \mathrm{mM} \mathrm{CaCl}{ }_{2}$ were transferred for acclimatisation (Figure 3c, 3d). This is the first report of transferring coconut plants developed through androgenesis into acclimatisation conditions.

\section{Effect of number of subcultures on necrosis}

Subculture of necrotic shoots into shoot multiplication medium at three-week intervals instead of six weeks did not significantly alleviate the problem of necrosis. It was revealed (Table 3 ) that there is no significant relationship between the number of subcultures and the occurrence of necrosis (Chi sq. $=0, p=1.00)$. The odds ratio 1 indicated that both levels have a similar chance of occurrence of necrosis.

Table 3: Effect of sub-culturing on shoot necrosis reduction.

\begin{tabular}{lc}
\hline Subculture interval (weeks) & $\%$ shoot necrosis \pm SD \\
\hline 3 & $56.25 \pm 06.25$ \\
6 & $56.25 \pm 18.75$ \\
\hline
\end{tabular}


Carbohydrate that acts as the source of carbon and energy during plant regeneration is a common, important component in coconut tissue culture media (Nguyen et al., 2015). Although sucrose is reported as the common sugar type in many of the plant tissue culture media (Yaseen et al., 2013), other sugars such as maltose, glucose and some tri-saccharides and pentoses have the potential to metabolise during androgenesis (Yaseen et al., 2013). According to the results obtained in the present study, the carbohydrate source is one of the major components that support the conversion of anthers into embryos. Both, the type of carbohydrate and carbohydrate concentration, affect the results obtained for the tested parameters. Out of the carbohydrates tested, sucrose and maltose were superior to glucose. A sucrose concentration of 90.0 $\mathrm{gL}^{-1}$ and maltose concentration of $120.0 \mathrm{gL}^{-1}$ showed significantly higher $(\mathrm{p}<0.05)$ embryo $(44.0 \%$ and 36.0 $\%$, respectively) production. Similar results of using high concentrations of sucrose have been reported elsewhere showing significantly higher embryo production in maize (Buter, 1997). Sucrose is an easily metabolised sugar, which shows a variety of effects on plant cell and tissue culture (Vitova et al., 2002). It is reported that sucrose can control the expression of pathogenesis-related genes in plants (Herbers et al., 1996). Moreover, it has been reported that high concentrations of carbohydrates improve embryogenesis by creating an osmotic stress (Agarwal et al., 2004). In addition under osmotic stress conditions, polyamine synthesis in plant cells increases causing favourable conditions for embryogenesis (Litz, 1986). However, sucrose levels higher than $90.0 \mathrm{gL}^{-1}$ showed an inhibitory effect on coconut anthers. Higher levels of sucrose $\left(150.0 \mathrm{gL}^{-1}\right)$ adversely affected the production of embryos (Figure 2). Similar observations on the reduction of embryo production upon elevated sucrose levels have been reported for species such as barley (Marsolais \& Kasha, 1985), rye (Guo \& Pulli, 2000), and Cucumis sativus (Ashok \& Murthy, 2004).

Maltose has been superior to sucrose as a carbohydrate source for androgenesis in several species including cereals. Culturing of barley microspores in media supplemented with sucrose, glucose, or fructose was found to be deleterious, whereas maltose acted favourably on embryo production (Scott \& Lyne, 1994). The capacity of barley microspores to differentiate and induce green plantlets has been enhanced by both maltose and malt extracts (Finnie et al., 1989). The effect has been determined in relation to the osmotic regulation of microspores during the induction phase (Sunderland \& Dunwell, 1977). However, in the present study maltose effect did not surpass the same observed in sucrose but showed similar results with sucrose at a comparatively higher concentration of maltose.

The effect of different concentration regimes of BAP on the conversion and further proliferation of embryos into shoots was investigated. BAP is considered as a chemically stable cytokinine in plant tissues and it is the commonly preferred cytokinine by plant tissue culturists (Klems et al., 2000). Initial work on coconut androgenesis has shown that conversion of embryos into plantlets is possible in the presence of $5.0 \mu \mathrm{M} \mathrm{BAP}$ (Perera et al., 2008; 2009). However, extremely low percentage $(7.0 \%)$ of shoot conversion has been reported. In a recent study, Perera et al. (2020) reported that BAP concentration plays a significant role in converting anther derived embryos into shoots. Maximum embryo sprouting has been reported in the media supplemented with 25.0 and $35.0 \mu \mathrm{m}$ BAP with a record of $50.0 \%$ and $53.0 \%$ conversions, respectively. However, the greatest shoot development recorded in the study conducted by Perera et al. (2020) was less than $30.0 \%$, in the medium supplemented with $35.0 \mu \mathrm{m}$ BAP. Nevertheless, in the present study, nearly $50.0 \%$ of the embryos were converted into plantlets when $20.0 \mu \mathrm{M}$ BAP was used. The use of modified $\mathrm{Y}_{3}$ medium formulated specifically for coconut in vitro culture instead of Murashige and Skoog medium is one of the major differences between these two studies. Moreover, different culture incubation durations in BAP incorporated media were maintained in these two studies.

Hormones usually tend to show the maximum shooting response at its optimum concentration. Farahani et al. (2008) reported that the shoot multiplication of Musa acuminata was affected by the concentration of BAP. Later in 2015, Ferdous et al. revealed the maximum single shoot formation and longest shoot formation in M. acuminata at $0.5 \mathrm{mg} / \mathrm{L}$ BAP. Similarly, determination of the precise concentration of BAP for maximum shoot regeneration has been reported in several other studies in different crop plants. Gubi et al. (2004), Kadota and Niimi (2003), Klems et al. (2000) and Jafari et al. (2011) reported that overexposure of cultures to higher concentrations of BAP might lead to hyperhydric shoots, which was not observed in the present study. However, Katoda and Niimi (2003) reported that the occurrence of hyperhydric cultures is less in BAP supplemented culture media when compared to media incorporated with synthetic cytokinines such as $N$-(2-chloro-4-pyridyl)-N9phenylurea (CPPU) and 1-phenyl-3- (1,2,3-thiadiazol5 -yl) urea (TDZ). Shoots consisting of single, double or multiple (Figure 1c) shoots were produced in BAP 
supplemented media, which is in accordance with the previous reports of coconut androgenesis (Perera et al., 2009). Ploidy analysis of coconut anther-derived plants has been performed previously on the current protocol by flow cytometry analysis and recorded a high double haploid yield (Perera et al., 2008). Thus, ploidy analysis studies were not executed for the current study since similar conditions were used as in the previous study.

Shoot necrosis is one of the obstacles associated with the androgenesis of coconut. The survival of shoots regenerated through androgenesis was difficult due to high shoot necrosis. An increase in calcium concentration in the regeneration medium from $2.0 \mathrm{mM}$ to $4.0 \mathrm{mM}$ has recorded higher recovery of anther-derived shoots affected by shoot necrosis, and reduced shoot necrosis from $84.21 \%$ to $25.00 \%$. Similar results have been reported in vitro for several other perennial crops such as grapes (Surakshitha et al., 2019), oak (Vieitez et al., 1989), banana (Martin et al., 2007) and Trichosantes dioica (Kishore et al., 2015). As discussed in previous reports, the occurrence of necrosis in coconut shoots developed through androgenesis may be associated with the calcium deficiency. Calcium is a major nutrient required for plant growth and it is responsible for the growth and differentiation of plant cells, formation of the cell wall, maintain membrane permeability and (Hepler, 2005; Stael et al., 2012). Thus, calcium deficiency in plant tissues could disturb metabolic activities in developing tissues, and as such, metabolic imbalances could be visualised as growth abnormalities like shoot necrosis (Surakshitha et al., 2019). According to Hirschi (2004), upward movement of calcium ion in the xylem sap is basically due to an efficient transpiration system. Therefore, it is suggested that conditions existing in the culture vessels that limit an efficient transpiration stream may be another way by which the mobility of calcium ions is limited in the in vitro plantlets, causing deficiency symptoms such as shoot necrosis. Since two times of the normal $\mathrm{Ca}^{+}$concentration of the $\mathrm{Y}_{3}$ medium was sufficient to reduce shoot necrosis, the effect may have caused low or no effect on shoot necrosis in this particular situation. The recovery or low necrosis in plantlets in high $\mathrm{Ca}^{+2}$ ion medium may be due to enhancing the mitotic process, possibly by regulating other hormonal signalling functions as described by Hepler and Wayne (1985). Bairu et al. (2009) reported that elevated BAP levels increased the occurrence of shoot necrosis in Harpagophytum procumbens.

However, mitigation of shoot necrosis was possible in the present study even at a higher BAP $(20.0 \mu \mathrm{M})$ concentration, when a $\mathrm{Ca}^{+2}$ rich medium was used.
Plantlets recovered in the $\mathrm{Ca}^{+2}$ rich medium were successfully acclimatised and subjected to greenhouse conditions (Figure 3d). Androgeneis is a highly genotype dependent activity (Bhatia et al., 2017). Since the modified protocol described above was developed for a Tall coconut variety, which is a cross pollinating variety, the successful application of adrogenesis in this variety will enable successful coconut breeding. When androgenesis protocols are being developed for other coconut varieties, the above mentioned facts could be considered to develop better protocols.

\section{CONCLUSIONS}

In conclusion, the present study demonstrated that manipulating different stages of androgenesis process in vitro could enhance the plantlet production up to a considerable level. Successful embryo production was achieved in sucrose and maltose when applied at 90.0 $\mathrm{gL}^{-1}$ or $120.0 \mathrm{gL}^{-1}$, respectively. Twenty micromolar (20 $\mu \mathrm{M})$ BAP showed the best shoot regeneration in anther derived embryos. The increase of $\mathrm{CaCl}_{2}$ concentration significantly affected alleviation of the problem of necrosis. Transfer of shoots at very early stages and continuous subculture of shoots into high $\mathrm{CaCl}_{2}$ containing $(4.0 \mathrm{mM})$ regeneration medium effectively reduced the occurrence of necrosis.

\section{Conflicts of interest:}

The authors have declared that there is no conflict of interest.

\section{Acknowledgments}

Financial assistance for the research was provided by the Coconut Research Institute, Sri Lanka through consolidate funds. Authors acknowledge Mrs. T.R. Gunathilake, Mr. E.S. Santha, Mrs. A. Keerthisinghe, and Ms. Nissansala Maduwanthie for the assistance given for culture maintenance. The authors also acknowledge Dr L.K. Weerakoon for reading the manuscript critically.

\section{REFERENCES}

Abdollahi M.R. \& Rashidi S. (2018). Production and conversion of haploid embryos in chickpea (Cicer arietinum L.) anther cultures using high 2,4-D and silver nitrate containing media. Plant Cell Tissue and Organ Culture 133: 39-49. DOI: https://doi.org/10.1007/s11240-017-1359-4

Agarwal S., Kanwar K. \& Sharma D.R (2004). Factors affecting secondary somatic embryogenesis and embryo maturation 
in Morus alba L. Scientia Horticulturae 102: 359-368. DOI: https://doi.org/10.1016/j.scienta.2004.04.002

Ashok K.H.G. \& Murthy H.N. (2004). Effects of sugars and amino acids on androgenesis of Cucumis sativus L. Plant Cell Tissue and Organ Culture 78: 201-208.

DOI: https://doi.org/10.1023/B:TICU.0000025637.56693.68

Bairu M.W., Jain N., Stirk W.A, Dolezal K. \& Staden J.V. (2009). Solving the problem of shoot-tip necrosis in Harpagophytum procumbens by changing the cytokinin types, calcium and boron concentrations in the medium. South African Journal of Botany 75: 122-127. DOI: https://doi.org/10.1016/j.sajb.2008.08.006

Bandupriya H.D.D., Femando S.C. \& Vidhanaarachchi V.R.M. (2016). Micropropagation and androgenesis in coconut: an assessment of Sri Lankan implication. Cocos 22: 31-47. DOI:https://doi.org/10.4038/cocos.v22i1.5810

Batugal P., Bourdeix R. \& Baudouin L. (2009). Coconut breeding. In: Breeding Plantation Tree Crops: Tropical Species (eds. S.M. Jain \& P.M. Priyadarshan), pp. 327-375. Springer, New York, USA.

DOI:https://doi.org/10.1007/978-0-387-71201-7_10

Bhatia R., Dey S.S., Parkash C., Sharma K., Sood S. \& Kumar R. (2018). Modification of important factors for efficient microspore embryogenesis and doubled haploid production in field grown white cabbage (Brassica oleracea var. capitata L.) genotypes in India. Scientia Horticulturae 233: 178-187.

DOI: https://doi.org/10.1016/j.scienta.2018.01.017

Bhatia R., Dey S.S., Sood S., Sharma K., Parkash C. \& Kumar R. (2017). Efficient microspore embryogenesis in cauliflower (Brassica oleracea var. botrytis L.) for development of plants with different ploidy level and their use in breeding programme. Scientia Horticulturae 216: 83-92.

DOI: https://doi.org/10.1016/j.scienta.2016.12.020

Buter B. (1997). In vitro haploid production in maize. In: In vitro Haploid Production in Higher Plants (eds. S. Mohan Jain, S.K. Sopory \& R.E. Veilleux), pp 37-71. Kluwer Academic Publishers, Dordrecht, The Netherlands. DOI: https://doi.org/10.1007/978-94-017-1862-2_2

Dunwell J. M. (1985). Anther and ovary culture. In: Cereal Tissue and Cell Culture (eds. S.W.J. Bright \& M.G.K. Jones), pp. 1-44. Matinus Nijhoff/ Dr. W. Junk Publishers, Dortrecht, The Netherlands.

DOI: https://doi.org/10.1007/978-94-009-5133-4_1

Eeuwens C.J. (1976). Mineral requirements for growth \& callus initiation of tissue explants excised from mature coconut palm (Cocos nucifera L.) cultured in vitro. Physiologia Plantarum 36: 23-28.

DOI: https://doi.org/10.1111/j.1399-3054.1976.tb05022.x

Farahani F., Aminpoor H., Sheidai M., Noormohammadi Z. \& Mazinani M.H. (2008). An improved system for in vitro propagation of banana (Musa acuminate L.) cultivars. Asian Journal of Plant Sciences 7: 116-118. DOI:https://doi.org/10.3923/ajps.2008.116.118

Ferdous M.H., Billah A.A.M., Mehraj H., Taufiqu T. \& Uddin A.F.M.J. (2015). BAP and IBA pulsing for in vitro multiplication of banana cultivars through shoot-tip culture. Journal of Biosciences and Agricultural Research 3: 87-95.

DOI:https://doi.org/10.18801/jbar.030215.35

Finnie S.J., Powell W. \& Dyer A.F. (1989). The effect of carbohydrate composition and concentration on anther culture response in barley (Hordeum vulgare L.). Plant Breeding 103: 110-118.

DOI: https://doi.org/10.1111/j.1439-0523.1989.tb00358.x

Gubi J., Lajchova Z., Farago J. \& Jurekova Z. (2004). Effect of growth regulators on shoot induction and plant regeneration in tomato (Lycopersicon esculentum Mill.). Biologia 59: 405-408.

Guo Y.D. \& Pulli S. (2000). Isolated microspore culture and plant regeneration in rye (Secale cereale L.). Plant Cell Reports 19: 875-880.

DOI: https://doi.org/10.1007/s002990000194

Hepler P.K. (2005). Calcium: a central regulator of plant growth and development. Plant Cell 17: 2142-2155.

DOI: DOI: https://doi.org/10.1105/tpc.105.032508

Hepler P.K. \& Wayne R.O. (1985). Calcium and plant development. Annual Review of Plant Physiology 36: 397-439.

DOI:https://doi.org/10.1146/annurev.pp.36.060185.002145

Herbers K., Meuwly P., Frommer W.B., Métraux J.P. \& Sonnewald U. (1996). Systemic acquired resistance mediated by the ectopic expression of invertase: possible hexose sensing in the secretory pathway. Plant Cell 8: 793-798.

DOI: https://doi.org/10.1105/tpc.8.5.793

Hirschi K.D. (2004). The calcium conundrum. Both versatile nutrient and specific signal. Plant Physiology 136: 2438 2442.

DOI: https://doi.org/10.1105/tpc.8.5.793

Jafari N., Othman R.F. \& Khalid K. (2011). Effect of benzylaminopurine (BAP) pulsing on in vitro shoot multiplication of Musa acuminata (banana) cv. Berangan. African Journal of Biotechnology 10: 2446-2450.

Kadota M. \& Niimi Y. (2003). Effect of cytokinin types and their concentration on shoot proliferation and hyperhydricity in in vitro pear cultivar shoots. Plant Cell Tissue and Organ Culture 72: 261-265.

DOI: https://doi.org/10.1023/A:1022378511659

Kishore K., Patnaik S. \& Shukla A. K. (2015). Optimization of method to alleviate in vitro shoot tip necrosis in Trichosantes dioica Roxb. Indian Journal of Biotechnology 14: 107-111.

Klems M.J., Balla J., Machackova I., Eder J. \& Prochazka S. (2000). The uptake and metabolism of H-3benzylaminopurine in tobacco (Nicotiana tabacum L.) and cucumber (Cucumis sativus L.) explants. Plant Growth Regulation 31: 135-142.

DOI: https://doi.org/10.1023/A:1006374611228

Litz R.E. (1986). Effect of osmotic stress on embryogenesis in Carica suspension culture. Journal of the American Society for Horticultural Science 111: 969-972.

Marsolais A.A. \& Kasha K.J. (1985). The role of sucrose and auxin in a barley anther culture medium. Canadian Journal 
of Botany 63: 2209-2212.

DOI:https://doi.org/10.1139/b85-313

Martin K.P., Zang C.L., Slater A. \& Madassery J. (2007). Control of shoot necrosis and plant death during micropropagation of banana and plantain (Musa spp.). Plant Cell Tissue and Organ Culture 88: 51-59.

DOI: https://doi.org/10.1007/s11240-006-9177-0

Nguyen Q.T., Bandupriya H.D.D., Villalobo A.L., Sisunandar S., Foale M. \& Adkins S.W. (2015). Tissue culture and associated biotechnological interventions for the improvement of coconut (Cocos nucifera L.): a review. Planta 242: 1059-1076.

DOI: https://doi.org/10.1007/s00425-015-2362-9

Perera P.I.P., Hocher V., Verdeil J-L., Bandupriya H.D.D., Yakandawala D.M.Y. \& Weerakoon L.K. (2008). Androgenic potential of coconut (Cocos nucifera L.). Plant Cell Tissue and Organ Culture 92: 293-302. DOI: https://doi.org/10.1007/s11240-008-9337-5

Perera P.I.P., Motha K.H. \& Vidhanaarchchi V.R.M. (2020). Morphological and histological analysis of anther-derived embryos of coconut (Cocos nucifera L.). Plant Cell Tissue and Organ Culture 140: 685-689.

DOI: https://doi.org/10.1007/s11240-019-01762-9

Perera P.I.P., Yakandawala D.M.Y., Hocher V., Verdeil J-L. \& Weerakoon L.K. (2009). Effect of growth regulators on microspore embryogenesis in coconut anthers. Plant Cell Tissue and Organ Culture 96: 171-180.

DOI: https://doi.org/10.1007/s11240-008-9473-y

Rajcan I., Boersma J.G. \& Shaw E.J. (2011). Plant genetic techniques: plant breeder's toolbox. In: Comprehensive Biotechnology, second edition (ed. M.M. Young), pp. 133147. Academic Press, USA.
DOI::// https doi.org/10.1016/B978-0-08-088504-9.00252-X

Scott P. \& Lyne R.L. (1994). The effect of different carbohydrate sources upon the initiation of embryogenesis from barley microspores. Plant Cell Tissue and Organ Culture 36: 129-133. DOI: https://doi.org/10.1007/BF00048323

Stael S., Wurzinger B., Mair A., Mehlmer N., Vothknecht U.C. \& Teige M. (2012). Plant organellar calcium signalling: an emerging field. Journal of Experimental Botany 63: 15251542 .

DOI: https://doi.org/10.1093/jxb/err394

Sunderland N. \& Dunwell J.M. (1977). Anther and pollen culture In: Plant Tissue and Cell Culture (ed. H.E. Street), pp. 223-265, Botany Monographs volume 11. Blackwell Scientific Publications. Oxford, London.

Surakshitha N.C., Soorianathasundaram K., Ganga M. \& Raveendran M. (2019). Alleviating shoot tip necrosis during in vitro propagation of grape cv. Red Globe. Scientia Horticulturae 248: 118-125.

DOI: https://doi.org/10.1016/j.scienta.2019.01.013

Vieitez A.M., Sanchez C. \& San-Jose C. (1989). Prevention of shoot tip necrosis in shoot cultures of chestnut and oak. Scientia Horticulturae 41: 101-109. DOI: https://doi.org/10.1016/0304-4238(89)90059-9

Vitova L., Stodulkova E., Bartonickova A. \& Lipavska H. (2002). Mannitol utilisation by celery (Apium graveolens) plants grown under different conditions in vitro. Plant Science 163: 907-916. DOI: https://doi.org/10.1016/S0168-9452(02)00240-6

Yaseen M., Ahmad T., Sablok G., Standardi A. \& Hafiz I.A. (2013). Role of carbon sources for in vitro plant growth and development. Molecular Biology Reports 40: 2837-2849. DOI: https://doi.org/10.1007/s11033-012-2299-z 